\author{
Баребина Н. С.
}

\begin{abstract}
Аннотация. Цель работы состоит в том, чтобы определить роль аргументативных пороков в трансформации медиадискурса. Научная новизна заключается в описании сущности адресантности аудитории-наблюдателя с помощью критической дискуссии как методологической абстракции, используемой в теории аргументации. В результате охарактеризованы ошибки аргументации, которые затемняют смысл, влияют на исход дискуссии, способствуют карнавализации и игровизации дискурсивной практики публичной дискуссии. Описана новая ошибка аргументации «недоверие эксперту» и выявлена стратегия экстраполирования негативного образа участника дискуссии на предмет обсуждения.
\end{abstract}

\title{
EN Argumentative Mistakes as Factor in Media Discourse Transformation (by the Example of Public Discussion Scripts)
}

\section{Barebina N. S.}

\begin{abstract}
The paper aims to reveal argumentative mistakes role in the media discourse transformation. Scientific originality of the study lies in the fact that the author describes essence of an addresser/observer's position by the example of critical discussion as methodological abstraction applied in argumentation theory. The research findings are as follows: the author identifies argumentative mistakes that distort the meaning, influence the discussion outcome, promote carnivalization and gamification of the public discussion discourse. A new argumentative mistake "expert distrust" is described and the strategy to extrapolate the negative image of a discussion participant to the discussed issues is revealed.
\end{abstract}

\section{Введение}

Объединение социальных сфер и сферы личностного общения, которое наблюдается в эру Интернета, породило формы мультимодальной коммуникации, способствующие преобразованию медийного дискурса. Функциональный аспект дискуссий в условиях гибридных форм коммуникации приобретает черты, не свойственные этому действию ни с позиций эвристики, ни с позиций речевого воздействия. Радикальные изменения, которые происходят в медийном дискурсе, требуют исследования роли аудитории в условиях современных медиаплатформ. Актуальность данной темы обусловлена влиянием малоизученной категории коммуникативной лингвистики - косвенного субъекта коммуникации - на коммуникативные характеристики медиадискурса. Проблема заключается в том, что категория адресата широко исследуется в прямом диалоге между адресантом и адресатом. Косвенный субъект коммуникации все еще представляет собой широкий и неопределенный круг адресатов, обозначаемых термином «аудитория», и исследуется далеко не в таких масштабах.

Цель статьи предполагает решение нескольких задач: 1) представить сведения об аргументативных пороках в связи с ошибками аргументации в скриптах дискуссий; 2) проанализировать текстовый чат с сообщениями зрителей и выявить фиксацию ими аргументативных ошибок; 3) рассмотреть роль нерациональных ходов в аргументации в трансформации медиадискурса.

Практическая значимость работы состоит в том, что материалы исследования могут быть использованы в вузах гуманитарного направления при изучении теории и практики аргументации, спецкурсов по развитию навыков критического мышления. Полученные данные могут найти применение при создании учебных пособий по медиажурналистике.

Теоретико-методологическую базу исследования составили работы по логико-лингвистическому подходу исследования аргументации Л. Г. Васильева [2], логико-когнитивной теории аргументации Е. Н. Лисанюк [10], 
коммуникативной лингвистике и дискурсологии В. И. Карасика [6; 7], прагма-диалектической теории аргументации Ф. Х. ван Еемерена [18].

Методы анализа. Дискуссия в работе понимается как «функциональная абстракция для изучения и моделирования» [10, с. 13] реально существующей языковой практики спора в институциональном общении. Использовался метод прагма-диалектической реконструкции [4] аргументативных шагов в дискуссии для выявления минимального аргументативного комплекса («аргумент $\rightarrow$ инференция $\rightarrow$ тезис»). Данные процедуры анализа далее позволили оценить рациональность аргументации и контраргументации участников и выявить ошибки. Синхронно методом сплошной выборки проводился анализ сообщений в чате аудитории, находящейся в прямом эфире, на предмет фиксации выявленных ошибок и их комментариев. Материалом исследования послужили скрипты пяти дискуссий в рамках авторского шоу К. Собчак на онлайн-платформе YоuTube общей продолжительностью 5 часов 8 минут. Выбор этой программы обусловлен тем, что она является одним из проектов, представляющих собой пока еще малоизвестный, но уже очень популярный формат журналистики. В рамках данной статьи представлен разбор одного выпуска и комментариев аудитории в количестве 18835.

\section{Косвенный субъект аргументации}

Считаем, что принятые в современной литературе трактовки термина «аудитория» [3; 23] необходимо дополнить характеристиками, связанными со способами упорядочения коммуникации и агентивностью. В этом случае аудитория медиа с точки зрения формата и партнерства в коммуникации не является прямым адресатом сообщений. В работе А. В. Полонского имеются указания на формат интерперсональной коммуникации в присутствии наблюдателя. Ученый отмечает, что в таком взаимодействии «говорящий всегда ориентируется на конкретного, присутствующего адресата, который выступает как личность с присущими ей особенностями <...> Наблюдатель при этом также выступает как конкретная личность или группа лиц, оценки которой являются релевантными для говорящего» [13, с. 11].

Сходное понимание наблюдателя как агента в непрямой коммуникации находим в моделях аргументации, основанных на неформальной логике и прагма-диалектике [18; 20], где убедительность позиций агентов в «споре-убеждении определяется при помощи характеристической функции “рационального судьи” [10, с. 14]. Данный агент вводится для оценки аргументов независимо от прямого адресата, но при этом он не взаимодействует напрямую с адресантом или адресатом. Воспользуемся конструктом «рациональный судья» для исследования аудитории как косвенного субъекта жанра публичной дискуссии.

\section{Ошибки аргументации как аргументативные пороки, ведущие к трансформации медиадискурса}

В современной аргументационной теории спор понимается как процесс обмена мнениями, направленный на устранение разногласий сторон. Разработана четырехчастная модель критической дискуссии, включающая стадию аргументации [4]. В случае диалога данная стадия представляет собой вопросно-ответную процедуру как «особый тип и способ рассуждения, который включает в себя в свернутой форме различные классические формы рассуждений» [14, с. 73]. На практике стороны систематически совершают неправильные ходы в аргументативной дискуссии. Этот факт был осмыслен с точки зрения логики и принципов кооперации и стал базисом для описания ошибок аргументации [19; 21;22; 24]. Выделяются три категории ошибок:

1) формальные или логико-категориальные ошибки, например, «круг в доказательстве», «ложная аналогия», «предвосхищение основания»;

2) словесные уловки, например, двусмысленность, неуместное гипостазирование, одноименность;

3) большая группа неформальных ошибок ad hoc, то есть ошибок особого случая («аргумент к личности», «аргумент к последствиям», «аргумент к незнанию», «аргумент к большинству», нахождение легко критикуемого единомышленника).

В свете эпистемологии добродетелей [9; 15] А. Р. Каримов в ряду других ключевых эпистемических добродетелей обосновывает аргументативную добродетель [8]. В соответствии с тем, что аргументативными пороками следует считать отклонения от идеала добродетели в дискуссии, авторы выделяют пять крайностей: 1) нежелание вступать в дискуссию; 2) нежелание слушать других; 3) нежелание изменять свою позицию в ходе аргументации; 4) нежелание подвергать сомнению очевидное; 5) интеллектуальное высокомерие [8; 16; 17]. При этом А. Р. Каримов доказывает, что пороки этой классификации ведут к тем или иным ошибкам или неверным ходам в дискуссии.

\section{Трансформация медиадискурса в жанре публичной дискуссии}

По наблюдениям В. И. Карасика, медийный дискурс претерпевает ряд трансформаций. Среди трансформаций, описываемых ученым [6, с. 249], выделим с некоторыми уточнениями те, которые наиболее характерны для описываемого нами жанра:

- $\quad$ качественное изменение канала коммуникации от печатных СМИ к кроссплатформенным мессенджерам с возможностью организовывать разные каналы, обмениваться информацией разных форматов; 
- смещение фокуса восприятия информации с рационального модуса в сторону эмоционального (комментарии, голосования, репосты, «лайки», антипатии);

- карнавализация медийного дискурса.

Основываясь на работах В.И. Карасика [6, с. 252; 7, с. 183], примем определение медийного дискурса как гибридного типа институционального общения, целью которого является оказание воздействия на заинтересованную аудиторию. Одним из жанров такого дискурса является публичное обсуждение каких-либо спорных вопросов. Участниками этого общения являются журналист, выполняющий функции модератора, приглашенные эксперты и аудитория в виде большого количества комментаторов. Мы сделаем уточнение о том, что обсуждение спорных вопросов содержит диалогические ходы, содержание которых с разной степенью эксплицитности представляет собой аргументацию мнений по обсуждаемому вопросу.

Аргументативный компонент четко выражен в жанре дискуссии. Приведем выдержки из выпуска «Осторожно: спор! За прививку или против» от 4.07.2021 г. Формат передачи - полемика между противником (д. мед. н., проф. А. А. Редько) и сторонником (к. биол. н., научный сотрудник А. Ю. Панчин) прививки от COVID-19 в прямом эфире. Ведущая - автор шоу К. Собчак (скрипт составлен с сохранением особенностей устной речи участников). Обозначим дискуссантов согласно предписанным им ведущей ролям: В - «вакцинатор»А. Ю. Панчин и А - «антивакцинатор» - А. А. Редько.

В.: Спутник используется более чем в 60 странах, сейчас недавно вышла новость, что в Сан-Марино, где, кстати, 80 процентов населения вакцинировали спутником, в неделю не было ни одного нового случая коронавируса. Это пример, доказывающий эффективность вакцинации. Что касается того, что вакцина якобы не исследована, уже давно вышла статья в журнале Lanсеt с промежуточными итогами третьей фазы клинических испытаний.

А.: Где это опубликовано?

В.: Любой желающий может погуглить и найти в Интернете эти данные, их все уже видели.

А.: Ничего подобного, никто не нашел, это интернет-публикация. Это научная публикация? В каком журнале, назовите.

В.: Посмотрите в Интернете.

А.: Как можно судить о таких серьезных вещах на основании интернет-публикации, вы же ученый. А журнал Lancet отозвал эту публикацию, потому что требовалось уточнение данных, вы разве не знали [12]?

В данном фрагменте выявляется аргументация оппонента. Реконструируем рассуждение и приведем его запись с помощью принятой в прагма-диалектическом анализе нотации:

1. Вакцина «Спутник» является эффективным средством от коронавирусной инфекции (тезис).

1.1. Вакцина «Спутник» эффективно используется в 60 странах.

1.1.1.Ни одного нового случая коронавируса за неделю в Сан-Марино, где 80\% населения вакцинировали «Спутником».

1.2. Журнал Lancet опубликовал данные о заключительном этапе испытаний этой вакцины.

Вид логической связи - индукция.

Данный пример иллюстрирует одно из ключевых правил аргументации - аргументы (в данном случае аргументы $1.1,1.1 .1,1.2$ ) должны быть доказанными фактами. Оппонент легко разрушает аргументацию, указав на ненадежность источника и на недоказанность факта в научной статье. Считается, что если хотя бы один аргумент опровергнут, то весь тезис не доказан.

Приведем два комментария зрителей на этом этапе диалога (некоторые комментарии отредактированы):

(1) Панчин врет и не краснеет. Ланцет 12 мая опубликовал новую статью о Спутнике. В ней отмечены расхождение данных и некачественная отчетность по третьей фазе. ВОЗ не признала Спутник вакциной.

(2) Че он звездит - в Сан-Марино только сегодня вакцинировано 68\% - Панчин врет нагло [Там же]!

Рассмотрим еще пример.

А.: Да, я считаю, что прививки от гриппа косвенно способствуют онкологии, они снимают температурную фазу, этому есть научные подтверждения.

Ведущая: Где они? Назовите.

А.: Это изложено в ряде весомых публикаций.

Ведущая: Назовите хоть одну.

А.: Хорошо, статьи П. П. Горбенко, за 2005-2006 год.

В.: (с усмешкой): Я вам найду статью, доказывающую, что ДНК можно телепортировать [Там же].

Данный фрагмент представляет собой попытку пропонента антивакцинатора подтвердить довод о том, что современная вакцина от коронавируса может привести к онкологии, опираясь на ранние данные по вакцине от гриппа. Схема аргументации - аналогия. Оппонент вправе требовать доказательств, и ведущая, которая заняла эту позицию, требует доказательства заявленного факта. Пропонент тоже играет свою диалектическую роль, которая включает бремя доказывания, лежащее на утверждающем (максима количества Г. П. Грайса - «говори столько, сколько нужно»). В ходе дискуссии этот аргумент так и остался недоказанным. Хотя сам по себе этот аргумент антивакцинатора также представляет собой разновидность ошибки аргументации (ad verecundiam - апелляция к авторитету), однако его нельзя полностью признать таким, ведь приводится мнение не физика или литератора, а эксперта. Но обращает на себя внимание реплика вакцинатора, который не признает авторитета ученого, опубликовавшего статьи по этой теме. В данном случае мы видим явление карнавализации, которое, по мнению ряда авторов, характерно для современного медийного дискурса $[1 ; 5 ; 11]$. Дискуссант карнавально переворачивает содержание реплики оппонента, переводя ситуацию 
в план комического противопоставления научных данных и развлекательного сюжета. После этого дискуссия пошла по другому пути, однако формат статьи не позволяет привести ее далее.

Комментарии зрителей содержат доводы в пользу аргумента антивакцинатора:

(3) Всемирно известный педиатр Роберт Мендельсон по поводу вакцинации детей написал: «Не сменили ли мы свинку и корь на рак и лейкемию».

Рассмотрим еще пример нарушения аргументации.

А.: Мой оппонент не прав, искусственный и естественный иммунитет - это не одно и то же.

Ведущая: А что, в чем разница?

А.: Искусственный иммунитет - очень узкий.

Ведущая (обращаясь к биологу-вакцинатору): Да? Это так?

В.: Нет, они по своему механизму не отличаются.

Ведущая (обращаясь к антивакцинатору): Я хочу понять, чем они отличаются. Тогда получается, что естественное оплодотворение отличается от искусственного, если говорить про результат?

А.: Конечно, отличаются. Но зачем вы сейчас про это говорите?

Ведущая: То есть ЭКО - это плохо [12]?

Данный виток дискуссии представляет собой контраргументацию антивакцинатора по поводу тезиса Искусственный и естественный иммунитет не различаются. Ведущая требует доказательств, и мы видим интересное явление, которое неоднократно повторяется в ходе дискуссии. Получив ответ от оппонента, ведущая обращается за подтверждением к другой стороне. Недоверие эксперту, казалось бы, безобидное, но имеет далеко идущие последствия для всей беседы.

Далее ведущая допускает грубую логическую ошибку, известную как мнимая логическая связь, когда желательная логическая связь выдается за истинную (non sequitur). То, что естественное оплодотворение отличается от искусственного, не означает, что последнее - это плохо. Однако ведущая провела именно эту посылку, а оппонент не смог ее вовремя распознать. Среди комментариев мы не нашли указания на это упущение.

Фрагмент содержит и словесную уловку - неверное терминоупотребление, а именно применение слов «искусственный» и «естественный» к двум разнородным категориям (иммунитет и оплодотворение). Поэтому дискуссия уходит в область этического:

А.: Конечно, если вы уж затронули эту тему, я сейчас все здесь разнесу. Мы делаем ЭКО, а зато 30000 ребятишек отправляем за границу ежегодно на усыновление.

Ведущая: Нет, давайте о медицинском.

А.: Так вот не надо это трогать [Там же].

На нарушение логической связи указывают комментарии (пример 4, 5):

(4) Искусственное оплодотворение осуществляется естественной яйцеклеткой и естественным сперматозоидом, а не при помощи компьютерного моделирования, как так называемая вакцина Спутник $V(5)$.

(5) Если ты, Ксенья, до сих пор не поняла, чем отличается искусственное оплодотворение от естественного, тебе уже поздно понимать, чем отличаются естественные антитела от продуктов вакцины мутирующего вируса. Зачем ты вставляешься в диалог?

Рассмотрим следующую ошибку.

А.: (обращаясь к оппоненту): Не может быть, что искусственный иммунитет одинаков с естественным. Дайте справку, кто когда сказал, что искусственный иммунитет такой же, как естественный.

Ведущая (обращаясь к антивакцинатору): Ну а чем он отличается? Конкретно.

А.: Во-первых, он в 10 раз более короткий.

Ведущая (обращаясь к биологу): Это так?

В.: Он эти циифры из головы берет.

$<\ldots>$

А.: (обращаясь к ведущей): Почему сегодня мой оппонент является экспертом? Если я заявляю одно, а вы спрашиваете у него, так это или нет [Там же].

В данном фрагменте антивакцинатор продолжает контраргументацию по отношению к тезису: Искусственный и естественный иммунитет не различаются и вполне обоснованно требует доказательств. Возможно, доказательства бы и последовали, но ведущая перекладывает бремя доказывания на того, кто их требует (эллиптическая конструкция Ну а чем он отличается?). Но далее снова демонстрируется недоверие ответу эксперта в виде обращения за консультацией к его противнику. Эта изматывающая тактика усугубляется и речением самого вакцинатора, применяющего по отношению к антагонисту в дискуссии местоимение он. В экспертном сообществе все же принято упоминать имя или должность. Аудитория идентифицирует данную ошибку как атаку личности одной из сторон:

(6) Просто нападки на профессора Редько и ничего, отвратительное шоу. Редько, держитесь, мы с Вами.

Недоверие эксперту получило единичный отзыв:

(7) Ксения, от того что Вы перебиваете постоянно человека, являющегося профессионалом в той сфере, о которой идет речь (не зря же Вы его пригласили), и вставляете свое мнение, это не значит, что люди будут думать так, как Вы сказали.

В заключение приведем еще пример ошибочной аргументации. В представленном ниже фрагменте антивакцинатор отвечает на вопрос телезрителя в прямом эфире. Телезритель уличил этого участника дискуссии в неверном истолковании данных по двум странам и указал на это обстоятельство. 
А.: В Швеции умерло 13000 человек в 2020 году, а в Англии умерло 127000. В Англии живет 66 миллионов, а в Швеции живет 10 миллионов. Если составить пропорцию, то в Швеции должно было умереть 19, а не 13\%, как это утверждает зритель.

Ведущая: Но есть же статистика. В Израиле, где, например, 9 миллионов проживает.

А.: Я не понимаю, про что мы говорим.

Ведущая: Вот я вам и даю пример: в Швеции - 10, в Израиле - 9 миллионов населения. Сопоставимые страны. В Израиле в 1,5 раза меньше смертей. Вот, пожалуйста. Порядка 10000 тысяч человек умерло. Это проверено, это статистическая информация.

А.: Это в каком году?

Ведущая: В 20 и 21. Это статистическая информация.

А.: Необходимо посмотреть внимательно эти цифры.

Ведущая: Так я вам их и говорю.

А.: Уменя другие цифры.

Ведущая: Какие?

А.: Я сейчас их не помню.

Ведущая: Ну это странный спор. Я их помню точно...

А.: А я не помню все страны. Я никогда не говорю то, что я не знаю [Там же].

В данном примере рассуждение ведущей, которая взяла на себя роль эксперта, пошло по ошибке ложной дихотомии вида «требование вариантов». Если пропонент берется говорить о двух категориях, то он и должен говорить в рамках этих двух членов дихотомии А и не-А (Швеция и Англия). Поэтому неверно требовать от него высказаться по категории (Израиль), которая не входит в эту дихотомию (тем более что зритель этого и не просил). Как видим, вопрос зрителя остался нерешенным, а обсуждение ушло в плоскость препираний по поводу цифр. Надо отдать должное антивакцинатору, который изящно вышел из этого странного спора.

Это заметила и аудитория (пример 8):

(8) Редько спросили про Швецию, а она про Израиль.

Некоторые комментарии содержат опровергающие цифры (пример 9).

(9) В Израиле умерло за ВСЕ ВРЕМЯ 6429, по-моему, это чуть меньше, нежели 10000. Собчак, зачем лжешь?

Формат статьи не позволяет обсудить все разновидности ошибочных ходов аргументаторов и реакции на них аудитории. Отметим частые указания на неформальную ошибку «аргумент к личности» (пример 10).

Аудитория также отмечает некорректное поведение второго участника дискуссии и ведущей (пример 10, 11):

(10) Не понравилось, как Панчин хихикал над оппонентом-профессором. С мнением любого человека надо считаться и не унижать, если у него отличное от твоего мнение. Безобразие. Выступление Редько мне понравилось.

(11) Собчак ведет себя непрофессионально, ухмыляется, навязывает свое мнение.

Зритель выявляет и речевые ошибки участников диалога (но, правда, и сам допускает ошибку в тексте комментария):

(12) Напополам? Все таки, ведущая! Займитесь своей речью!

Также аудитория четко фиксирует нарушение различных норм ведения дискуссий, таких как роль модератора, например:

(13) Ксения, ваше мнение никого не интересует по данному вопросу - поймите это! Вы должны были быть объективны и беспристрастны. Чтобы увидеть истину, нужно отказаться от всех точек зрения!!! А так, получился базар какой-то...

В ходе передачи всем зрителям предлагается голосовать на Telegram-канале ведущей под названием «Кровавая барыня» и на канале ҮouTube. Результаты голосования таковы, что антивакцинатор и вакцинатор получили примерно равное количество голосов ( 54 и $46 \%$ и 57 и $43 \%$ соответственно). Комментариев относительно итогов дискуссии совсем немного. Вот примеры текстов комментариев об ее итоге:

(14) Очень сильная работа! Каждый показал себя в полной красе. Никто никого не переубедил. Каждый только усилил свою позицию в армии своих поклонников.

(15) Голосование на пеньке.

Более тревожными выглядят комментарии такого типа:

(16) Собчак ведёт себя неподобающе. Она склоняется на сторону сторонника вакцинации и не удерживает нейтралитет. Это вызывает протест как против неё, так и против вакцинации.

(17) Такое неуважение к оппоненту: высмеивание, издёвки со стороны сторонника вакцинации, и Собчак его всячески поддерживает. Это сильно бросается в глаза. Это меня склоняет к противнику вакцинации от ковида.

\section{Обсуждение результатов}

Анализ аргументативной составляющей дискуссии показал, что стороны, используя рассуждения для обоснования своих позиций, совершают ошибки. Эти неправильные шаги становятся фокусом критики аудитории. Наиболее частотным элементом в критике комплекса «аргумент $\rightarrow$ инференция $\rightarrow$ тезис» является аргумент. Наибольшее число замечаний выглядит как контрпримеры и опровержение ложных фактов. Эти случаи представляют собой цитаты, ссылки на мнение других экспертов, факты. Второй элемент аргументативного комплекса - «инференция» - также нередко становится предметом критических комментариев. Зафиксированы указание на нарушение связи аргумента и тезиса в форме ложной аналогии и на нарушение 
процесса индукции как логического вывода при переходе от частного к общему. Элемент «тезис» попадает в фокус критики в единичных случаях. Выглядит он нередко в виде контртезиса по отношению к точке зрения одной из сторон, например: Вакцину невозможно изготовить качественно. Мы связываем это с временно́й особенностью чата, а именно с тем, что критика тезиса, обсуждаемого непосредственными участниками дискуссии, требует больше времени и усилий.

Что касается неформально-логических ошибок аргументации, самое большое количество нареканий аудитории связано с нападками на личность (argumentum ad hominem). Зритель идентифицирует их, но интуитивно и эмоционально. Комментарии оформляются такими вокабулами и словосочетаниями, как жалко, высмеивание, издёвки, ёрничанье, неуважительное отношение, пожилой оппонент, клевать вдвоем, вести себя мерзко и вызывающе. Эта группа ошибок отмечена в 38\% комментариев. Это связано с тем, что эта ошибка систематически повторялась в ходе дискуссии, и именно эта разновидность ошибок выражена эксплицитно и сопровождается невербальными компонентами коммуникации в виде жестов, проксемики, мимики, окулесики. Хотя анализ скрипта дискуссии показывает и другие ошибки этой категории, такие как аргумент к последствиям (argumentum ad consequentiam) и аргумент к незнанию (argumentum ad ignorantiam).

Никто из зрителей не заметил неоднократно повторяющуюся ошибку перекладывания бремени доказывания на оппонента. Еще одну ошибку, описания которой мы не нашли в специальной литературе и которая пополнит список неформальных ошибок, мы назовем ошибкой недоверия эксперту. Она состоит в том, что если уж дискуссия организована при условии участия в ней лиц, обладающих достаточной квалификацией, то нет никаких оснований им не доверять. Поэтому обращаться за проверкой знаний эксперта не к независимому эксперту, а к эксперту-оппоненту, нерационально.

В 64\% всех комментариев аудитории содержатся указания на нарушения в процедуре проведения дискуссии. Поводом для негативных комментариев является отсутствие нейтралитета ведущей, которая встает на сторону вакцинатора. Притом что дискуссия имеет признаки карнавализации, действия ведущей имеют вполне конкретные и серьезные последствия. Они представляют собой экстраполяцию негативного отношения к участнику диалога на предмет обсуждения, что приводит к неадекватным выводам.

Отсутствие цензуры и «скучных» разговоров, которые являются частью современного ютьюб-шоу, однако, ведет и к оценке происходящего как абсурда, например: Бред!, Спектакль, Слет уфологов и плоскоземельщиков.

Если оценить выявленные ошибки и неверные ходы дискуссантов в терминах аргументативных пороков, представленных А. Р. Каримовым [8, с. 24], то такими отклонениями являются пристрастие в пользу одной стороны, неуместное рвение, равнодушие к очевидным фактам, чрезмерное внимание к деталям, неспособность изменить свою точку зрения и интеллектуальное высокомерие как неспособность оценить собственные интеллектуальные ограничения.

\section{Заключение}

В статье исследовалась проблема трансформации медиадискурса с помощью аргументативной дискуссии как методологической абстракции. Таким образом, рассмотрев аргументативные ошибки и реакции на них аудитории, мы приходим к следующим выводам.

1. Аргументативные пороки в рассмотренных дискуссиях выражаются в логико-категориальных ошибках, ошибках внелогического характера, нарушении коммуникативного кодекса и норм ведения дискуссии.

2. При общей установке на несерьезное общение в чате зритель дискуссии продолжает быть рациональным субъектом и способен выявить ошибки, которые приводят к неадекватным выводам в дискуссии. В оценке комплекса «аргумент $\rightarrow$ инференция $\rightarrow$ тезис» в фокус критики попадают первые два элемента, то есть факты и логическая связь. Наиболее часто субъектом аргументации фиксируются неформальные ошибки, связанные с эмоциями, дополняющиеся невербальной составляющей коммуникации.

3. Динамика общения в зрительском чате демонстрирует зависимость от аргументативных пороков, которые затемняют смысл основной темы обсуждения, формируют негативное или позитивное отношение к экспертам-участникам, влияют на исход дискуссии. Ошибочные ходы в диалоге, длительная фаза аргументации при сжатом, озвученном вскользь подведении итогов, свободный статус медиатора в сочетании с обсуждением серьезных социальных тем усиливают тенденцию к карнавализации и игровизации дискурсивной практики публичной дискуссии.

Перспективы дальнейших исследований мы видим в изучении влияния других логических и внелогических аспектов аргументации в дискуссиях с точки зрения развития аргументативных добродетелей участников коммуникативной реальности.

\section{Источники | References}

1. Буряковская В. А. Коммуникативные характеристики массовой культуры в медийном дискурсе (на материале русского и английского языков). Волгоград: Перемена, 2014. 228 с.

2. Васильев Л. Г. Аргументация и ее понимание: логико-лингвистический подход. Калуга: Калуж. гос. ун-т им. К. Э. Циолковского, 2014. 331 с. 
3. Евдокимов В. А. Аудитория масс-медиа как объект и субъект коммуникации // Наука о человеке: гуманитарные исследования. 2010. № 6. С. 136-142.

4. Еемерен Ф. Х. ван, Гроотендорст Р. Речевые акты в аргументативных дискуссиях. Теоретическая модель анализа дискуссий, направленных на разрешение конфликта мнений / пер. с англ. Е. А. Богоявленской. СПб.: Васильевский остров, 1994. 239 с.

5. Желтухина М. Р. Воздействие медиадискурса на адресата. Волгоград: Перемена, 2014. 91 с.

6. Карасик В. И. Языковая пластика общения. М.: Гнозис, 2021. 536 с.

7. Карасик В. И. Языковая спираль: ценности, знаки, мотивы. М.: Гнозис, 2019. 424 с.

8. Каримов А. Р. Глубокое разногласие и аргументативные добродетели // Общество: философия, история, культура. 2018. № 1. С. 21-24.

9. Каримов А. Р. Эпистемология добродетелей. СПб.: Алетейя, 2019. 428 с.

10. Лисанюк Е. Н. Логико-когнитивная теория аргументации: дисс. ... д. филос. н. СПб., 2015. 297 с.

11. Маклюэн М. Понимание Медиа: внешние расширения человека / пер. с англ. В. Николаева. М.: Жуковский; Канон-пресс-Ц, 2003. 464 с.

12. Осторожно: спор! За прививку или против [Электронный ресурс]: дебаты о вакцинации. URL: https://www.youtube. com/watch?v=nns7G5flDyU (дата обращения: 25.07.2021).

13. Полонский А. В. Категориальная и функциональная сущность адресатности: на материале русского языка в сопоставлении с польским: дисс. ... д. филол. н. Белгород, 1999. 451 с.

14. Сорина Г. В. Вопросно-ответная процедура в аргументационной деятельности // Теория и практика аргументации. М.: Ин-т философии РАН, 2001. С. 71-89.

15. Шевченко А. А. Эпистемология и добродетели // Сибирский философский журнал. 2016. Т. 14. № 4. С. 82-92.

16. Aberdein A. The vices of argument // Topoi. 2016. Vol. 35. № 2. P. 413-422.

17. Cohen D. Arguments that backfire [Электронный ресурс] // The uses of argument / ed. by D. Hitchcock, D. F. Hamilton. OSSA, 2005. P. 58-65. URL: https://philpapers.org/rec/COНАТВ-2 (дата обращения: 10.08.2021).

18. Eemeren F. H. van, Grootendorst R. A Systematic Theory of Argumentation: The Pragma-Dialectical Approach. Cambridge: Cambridge University Press, 2003. 210 p.

19. Groarke L., Tindale C. W. Good Reasoning Matters! A Constructive Approach to Critical Thinking. 3rd ed. Toronto: Oxford University Press, 2003. 488 p.

20. Hample D. The Arguers // Informal Logic. 2007. Vol. 27. № 2. P. 163-178.

21. Hansen H. V., Pinto R. C. Fallacies: Classical and Contemporary Readings. University Park: Pennsylvania State University Press, 1995. 368 p.

22. Walton D. N. Appeal to Expert Opinion: Arguments from Authority. University Park: Pennsylvania State University Press, 1997. 300 p.

23. Webster J. G. The Audience // Journal of Broadcasting \& Electronic Media. 1998. № 42. P. 109-207.

24. Woods J. H. The Death of Argument: Fallacies in Agent Based Reasoning. Dordrecht: Kluwer, 2004. 378 p.

\section{Информация об авторах | Author information}

RU Баребина Наталья Сергеевна ${ }^{1}$, д. филол. н.

${ }^{1}$ Байкальский государственный университет, г. Иркутск

EN Barebina Natalia Sergeevna ${ }^{1}, \mathrm{Dr}$

${ }^{1}$ Baikal State University, Irkutsk

${ }^{1}$ svirel23@rambler.ru

\section{Информация о статье | About this article}

Дата поступления рукописи (received): 16.07.2021; опубликовано (published): 15.09.2021.

Ключевые слова (keywords): дискуссия; аргументация; ошибки; медиадискурс; аудитория; discussion; argumentation; mistakes; media discourse; audience. 